\title{
The role of sterol regulatory element-binding proteins in mediating the effects of dietary lipids on hepatic gene expression in the hamster
}

\author{
Thomas Vallim, Andrew Bennett and Andrew Salter \\ University of Nottingham, Nottingham, UK
}

There is growing evidence to suggest that dietary lipids can regulate the expression of genes for proteins associated with lipid and lipoprotein metabolism. It has been suggested that many such affects are mediated by changes in the activity of the sterol regulatory element-binding protein (SREBP) transcription factors ${ }^{(1,2)}$. In general, SREBP1c has been identified as regulating lipogenic gene expression (e.g. acetyl-CoA carboxylase (ACC) and fatty acid synthase (FAS)), while SREBP2 regulates expression of enzymes involved in cholesterol synthesis (e.g. 3-hydroxyl-3-methylglutaryl-CoA reductase; HMGCoAred) and the LDL receptor (LDLr) ${ }^{(1,2)}$. SREBP are produced as 'immature' precursors that reside on the endoplasmic reticulum, which are then acted on by specific proteases to release the 'mature' active form $1^{(1,2)}$. Using the hamster as a model organism, the role of the SREBP (SREBP1c and SREBP2) in mediating the effects of dietary cholesterol and fat on the expression of these genes in the liver has been investigated.

Hamsters (eight per group) were fed one of four diets for $28 \mathrm{~d}$ : a high-carbohydrate-low-fat chow (chow); chow supplemented with $0.2 \%(\mathrm{w} / \mathrm{w})$ cholesterol (chol); chow supplemented with $15 \%(\mathrm{w} / \mathrm{w})$ fat, formulated to represent the fatty acid composition of a typical 'Western' diet (fat); chow supplemented with both (chol+fat). Animals were then killed, RNA was extracted from livers and steady-state mRNA concentrations were measured by real-time PCR. These results are expressed relative to the housekeeping gene TATA box-binding protein, which was not affect by diet. Protein was also extracted from liver and the amount of immature and mature SREBP1 and SREBP2 protein determined by Western blotting. Data was analysed by two-way ANOVA, exploring significant effects of chol, fat or an interaction between the two (chol $\times$ fat $)$.

\begin{tabular}{|c|c|c|c|c|c|c|c|c|c|c|}
\hline & \multicolumn{2}{|c|}{ Chow } & \multicolumn{2}{|c|}{ Chol } & \multicolumn{2}{|c|}{ Fat } & \multicolumn{2}{|c|}{ Chol + fat } & \multirow{2}{*}{\multicolumn{2}{|c|}{$P$}} \\
\hline & Mean & $\overline{\mathrm{SD}}$ & Mean & $\mathrm{SD}$ & Mean & SD & Mean & $\overline{\mathrm{SD}}$ & & \\
\hline SREBP1c & 0.85 & 0.31 & 0.99 & 0.31 & 0.64 & 0.15 & 0.95 & 0.22 & Chol & 0.019 \\
\hline SREBP2 & 1.19 & 0.22 & 0.88 & 0.23 & 1.03 & 0.26 & 0.64 & 0.13 & $\begin{array}{l}\text { Chol } \\
\text { Fat }\end{array}$ & $\begin{array}{r}<0.001 \\
0.015\end{array}$ \\
\hline LDLr & 2.06 & 0.41 & 0.99 & 0.14 & 1.19 & 0.25 & 0.94 & 0.26 & Chol $\times$ fat & $<0.001$ \\
\hline HMGCoAred & 1.32 & 0.35 & 0.92 & 0.10 & 1.06 & 0.19 & 0.79 & 0.12 & $\begin{array}{l}\text { Chol } \\
\text { Fat }\end{array}$ & $\begin{array}{r}<0.001 \\
0.015\end{array}$ \\
\hline $\mathrm{ACC}$ & 1.39 & 0.42 & 0.91 & 0.27 & 0.65 & 0.13 & 0.67 & 0.21 & Chol $\times$ fat & 0.019 \\
\hline FAS & 1.57 & 0.38 & 0.81 & 0.32 & 0.71 & 0.18 & 0.49 & 0.27 & Fat $\times$ chol & 0.020 \\
\hline
\end{tabular}

SREBP1c mRNA levels were not affected by dietary fat but were increased by dietary chol. However, no changes SREBP1 protein levels were apparent. By contrast, SREBP2 mRNA and protein levels (both immature and mature) were significantly decreased by both dietary fat and chol. The expression of each of the SREBP 'target' genes was reduced by dietary chol and fat with significant interactive effects on LDLr, ACC and FAS. The mRNA concentrations for each of these genes was highly correlated with SREBP2 mRNA $(P<0.001$ for each) but not with SREBP1c mRNA. These data confirm the regulation of LDLr and HMGCoAred expression by SREBP2, but further suggest that, at least in some circumstances, SREBP2 rather than SREBP1c may regulate the expression of lipogenic genes such as ACC and FAS. Further studies to demonstrate specific interaction of SREBP2 with the promoters of these genes are required to confirm this suggestion.

This work was supported by the British Heart Foundation.

1. Horton JD, Goldstein JL \& Brown MS (2002) J Clin Invest 109, 1125-1131.

2. Eberle D, Hegarty B, Bossard P, Ferre P \& Foufelle F (2004) Biochimie 86, 839-848. 